\title{
Chapter 6 \\ User Requirements When Designing Learning e-Content: Interaction for All
}

\author{
Pilar Orero and Irene Tor-Carroggio
}

\begin{abstract}
Learning is a fundamental Human Right and in the Information Society learning has become an audiovisual experience. Audiovisual interactive learning materials, virtual learning environments and platforms, and online applications are the standard format where learning happens. Having access to this e-learning environment and content is fundamental to fulfil the right to education, but also the UN Convention on the Rights of Persons with Disabilities, which mentions "nothing about us without us" leading to take into consideration persons with disabilities when designing all learning elements. Therefore, accessibility has to be integrated in every step of the design process to avoid costly and unsatisfactory ad hoc solutions. How to contact end users and request their information and participation is an unavoidable challenge. Questionnaires have been the traditional tool to enquire users about their needs and preferences. Still, how to draft pertinent questionnaires to gather meaningful information is not a straightforward activity, but one that varies with fashions and schools of thought. For example, the Medical and the Social Models share equal popularity to classify user disabilities. In this chapter we will depart from the fact that access to education is a Human Right, and from the experience of designing an accessible MOOC. The second part of the chapter will revise some of the most used models of disability and we will explore a more holistic approach based on user capabilities. This will allow researchers in Education to focus on the aspects they can provide a solution to, instead of dealing with physiological tags that offer a simplified view of reality.
\end{abstract}

This article is related to the research carried out in the European funded projects ImAC (GA: 761974) and EasyTV (GA: 761999). Both authors are TransMedia Catalonia members (2017SGR113, 2017).

P. Orero $(\varangle) \cdot$ I. Tor-Carroggio $(\bowtie)$

Universitat Autònoma de Barcelona, Barcelona, Spain

e-mail: pilar.orero@uab.cat

I. Tor-Carroggio

e-mail: irene.tor@uab.cat

E. Kapros and M. Koutsombogera (eds.), Designing for the User Experience

in Learning Systems, Human-Computer Interaction Series,

https://doi.org/10.1007/978-3-319-94794-5_6 


\subsection{Introduction}

Education is considered one of the most basic human rights. This can be read in Article 26 of the Universal Declaration of Human Rights. ${ }^{1}$

"Everyone has the right to education. Education shall be free, at least in the elementary and fundamental stages. Elementary education shall be compulsory. Technical and professional education shall be made generally available and higher education shall be equally accessible to all on the basis of merit. Education shall be directed to the full development of the human personality and to the strengthening of respect for human rights and fundamental freedoms. It shall promote understanding, tolerance and friendship among all nations, racial or religious groups, and shall further the activities of the United Nations for the maintenance of peace. Parents have a prior right to choose the kind of education that shall be given to their children."

The right to education is also mentioned in Articles 13 and 14 of the International Covenant on Economic, Social and Cultural Rights. ${ }^{2}$ The right to education has also been reaffirmed in the 1960 UNESCO Convention against Discrimination in Education, ${ }^{3}$ the 1981 Convention on the Elimination of All Forms of Discrimination Against Women (CEDAW), ${ }^{4}$ the 2006 Convention on the Rights of Persons with Disabilities (CRPD), ${ }^{5}$ and the African Charter on Human and Peoples' Rights. ${ }^{6}$

As early as 1952 in Europe, Article 2 of the first Protocol to the European Convention on Human Rights ${ }^{7}$ states that the right to education is recognized as a human right and is understood to establish an entitlement to education. This right encompasses also the obligation to eliminate discrimination at all levels of the educational system, to set minimum standards, and to improve quality.

Universal legislation regarding education is in place, still the Internet and the new Information Technology (IT) technologies have changed the field of education in general, and learning in particular. Learning possibilities and approaches have multiplied. The Internet has made possible new learning paradigms like Massive Online Open Courses (MOOC) (Seale 2014). The need to have an inclusive approach for learning is today more pertinent than ever to comply with all the above-mentioned legislation from the area of Human Rights (Sánchez-Gordón and Luján-Mora 2014, 2016; Iniesto and Rodrigo 2016; Orero 2017).

Technology allows for automatic translation of content, for interaction in virtual reality environments, and Artificial Intelligence (AI) will soon tailor our learning interests, recommendations, and will produce bespoke assessments. Still, the human factor is at the centre of all human learning activities and having the right of access

\footnotetext{
${ }^{1}$ See http://www.un.org/en/universal-declaration-human-rights/ [retrieved 14/03/2018].

${ }^{2}$ See https://treaties.un.org/Pages/showDetails.aspx ?objid=080000028002b6ed [retrieved 14/03/2018].

${ }^{3}$ See https://goo.gl/9oipD5 [retrieved 14/03/2018].

${ }^{4}$ See http://www.un.org/womenwatch/daw/cedaw/cedaw.htm [retrieved 14/03/2018].

${ }^{5}$ See http://www.ohchr.org/EN/HRBodies/CRPD/Pages/CRPDIndex.aspx [retrieved 14/03/2018].

${ }^{6}$ See http://www.achpr.org/instruments/achpr/ [retrieved 14/03/2018].

${ }^{7}$ See https://rm.coe.int/168006377c [retrieved 14/03/2018].
} 
to the e-ecosystem and its content is not yet a mainstreamed requirement when designing content.

Since many learning environments are online, each browser has its own tools allowing for alternative interaction. Much effort has been dedicated to design alternative interactive e-technology such as JAWS or Classroom Screen Reader, ${ }^{8}$ or the many speech-to-text programmes, and even a Google Draw Braille. ${ }^{9}$ Regarding web pages, the World Wide Web Consortium (W3C) launched the Web Accessibility Initiative (WAI) as an effort to improve the accessibility of the World Wide Web (WWW) for people with disabilities, and to fulfil the UN CRPD since people with disabilities and the elderly require non-standard devices and browsers. The W3C launched the Web Accessibility Initiative in 1997 and started working on the Web Content Accessibility Guidelines (WCAG). They are a set of guidelines that specify how to make content accessible, primarily for people with disabilities. The current version, WCAG 2.0, was published in December 2008 and became an ISO standard, ISO/IEC 40500:2012, in October 2012. ${ }^{10}$

While much effort has been made in the technical side of accessibility and e-learning, little dedication has been made to address the interaction and accessibility with the media learning content. Recently, the field of Media Accessibility was established as a "set of theories, practices, services, technologies and instruments providing access to audiovisual media content for people that cannot, or cannot properly, access that content in its original form (Szarkowska et al. 2013; Greco 2016). It is now established how technology is basic for Media Accessibility, since it determines the service, its production, distribution and reception, and it also has a direct impact on the quality. At the other side of the spectrum, we find the user who will be learning. The user, in a way, determines the technology to be used and also how to access the learning content.

\subsection{Accessible MOOC}

Designing an accessible MOOC is a challenge (Iniesto et al. 2014; Seale 2014). Accessibility requirements (Sánchez-Gordón and Luján-Mora 2016) should be met from: platform services, user interface, learning content and resources, and learning assessment activities. While much literature focuses on the platform interaction (Iniesto and Rodrigo 2016) and user interface requirements (Ngubane-Mokiwa 2016) little is dedicated to the content or assessments (Sánchez-Gordón and Luján-Mora 2014). This difference is probably due to the nature, field of knowledge, and format of the learning content. It is not the same to access mathematical formulae or statistics than to read a music score or follow any of these as a PowerPoint presentation or a movie. Multiplicity of topics and formats defy unified solutions or guidelines

\footnotetext{
${ }^{8}$ See http://bit.ly/2D1sKA1 [retrieved 18/01/2018].

${ }^{9}$ See https://support.google.com/docs/answer/6057417 [retrieved 18/01/2018].

${ }^{10}$ See https://www.iso.org/standard/58625.html [retrieved 18/01/2018].
} 
following a mainstreamed Universal Design approach (Ngubane-Mokiwa 2016). Also, the multiple end user requirements should be taken into consideration, and to this aim the first accessible MOOC on media accessibility was designed in 2015 for the EU funded project HBB4ALL. ${ }^{11}$ HBB4ALL MOOC had a double objective. The content of the course teaches the many issues related to accessibility services for media content: subtitling, audio description and Sign Language interpreting. The course interaction is in itself a demo on how to make MOOCs content accessible. This was a timely proposal since existing prestigious MOOCs, such as those from Harvard University and MIT, have been sued for their lack of accessibility ${ }^{12}$ and Bohnsack and Puhl (2014) showed how none of the largest platforms (Udacity, Coursera, edX, OpenCourseWorld and Iversity) were accessible or allowed for accessible content beyond sound transcription.

HBB4ALL MOOC took into consideration the following accessibility user requirements:

- Visual media had to be accessible for persons with sight and low vision impairments.

- Spoken dialogue had to be subtitled in the same language, for people with hearing impairments.

- The module on Sign Language needed an interpretation into Sign Language, for deaf users.

For this we prepared subtitles, audio description and Sign Language as the basic services interaction access services. While subtitling is the most widespread service, Sign Language interpretation is perhaps the most obvious. The reason is because it takes a good share of the screen, and it presents two videos simultaneously challenging the challenging viewers with split attention (Fig. 6.1).

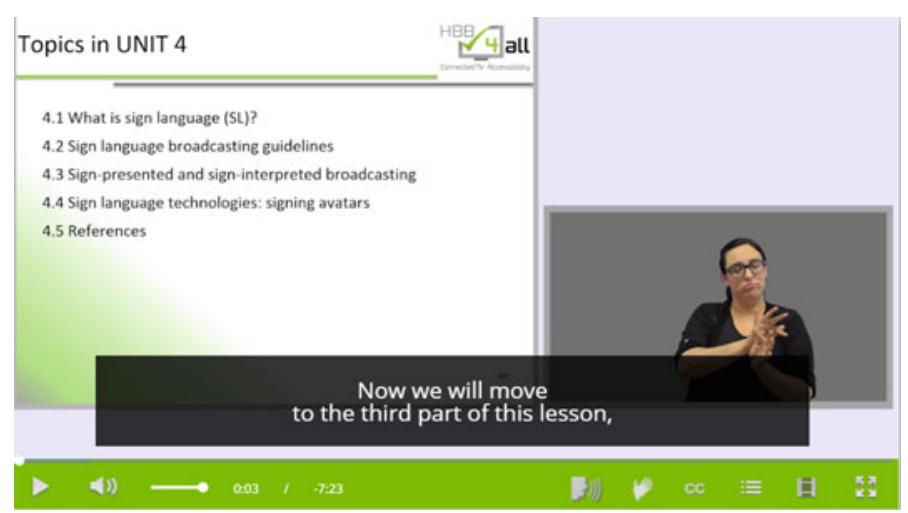

Fig. 6.1 Subtitles, PPT and Sign Language screen sharing student attention

\footnotetext{
${ }^{11}$ See http://accessguide.tv/course/ [retrieved 14/03/2018].

${ }^{12}$ See https://goo.gl/vqdjv6 [retrieved 14/03/2018].
} 
For the HBB4ALL MOOC the platform used was developed as part of the project, and other user requirements, such as multilanguage, while available in the technological side, were not possible given the cost of translations. EMMA, ${ }^{13}$ the EU funded multilanguage MOOC platform, allows for this, solving one of the biggest accessibility issues, since in Europe the wealth of languages challenges the sharing learning materials because of language specific content (Sánchez-Gordón and Luján-Mora 2015).

The personalisation of the MOOCs accessibility features was built with an online platform called AccessGUIDE. It allows the personalisation of accessible online video services on PCs and mobile platforms. This Software is a Service (SaaS) platform that can be used by application developers to include personalized accessibility features into their applications. It comes along with an online multilingual text-tospeech function that can be used for screen reader and spoken subtitle functionality. It supports the personalisation of the applications' user interface, the subtitles in video on demand applications as well as the text-to-speech service.

AccessGUIDE service supports accessibility features such as a screen reader functionality (Fig. 6.2), customizable multilingual subtitles with the possibility of choosing language, size and position (Fig. 6.3), spoken subtitles in different languages as well as the possibility to switch between signed and unsigned video content (Fig. 6.4).
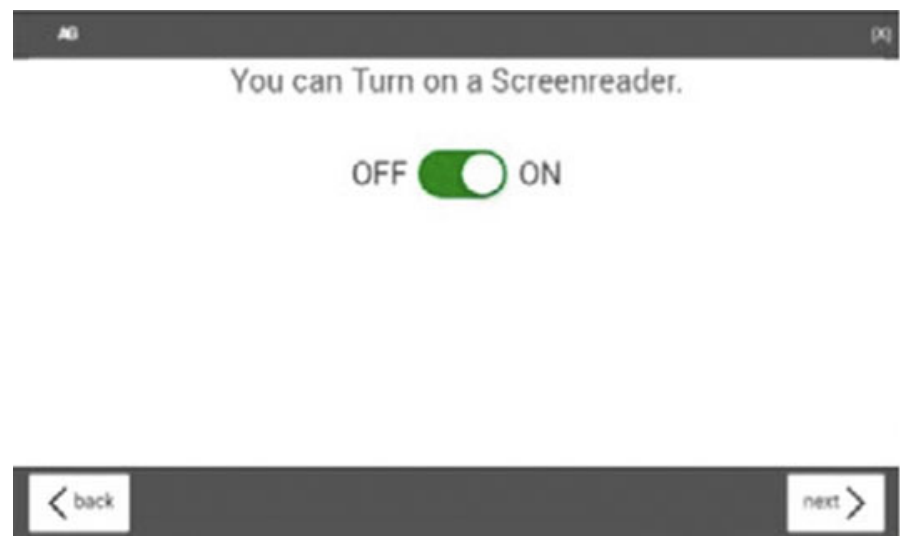

Fig. 6.2 Screen reader functionality

\footnotetext{
${ }^{13}$ See http://project.europeanmoocs.eu/about/ [retrieved 14/03/2018].
} 

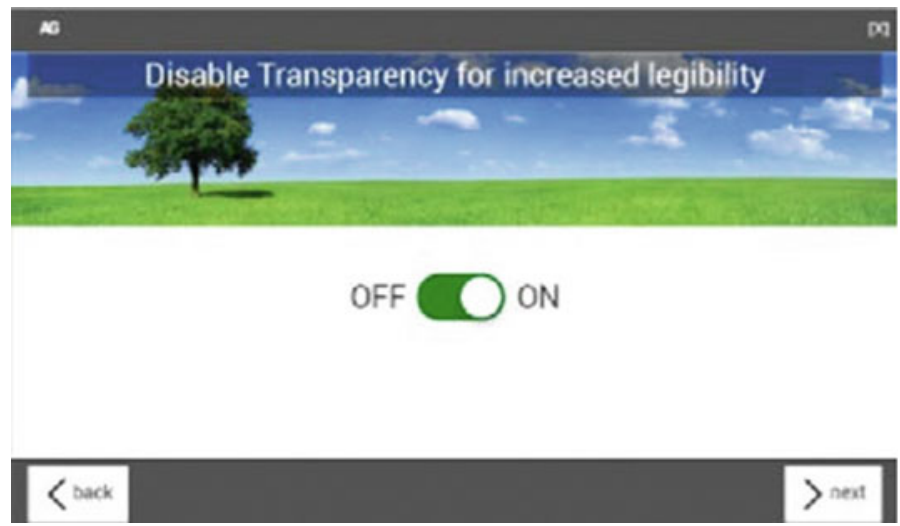

Fig. 6.3 Subtitle personalisation

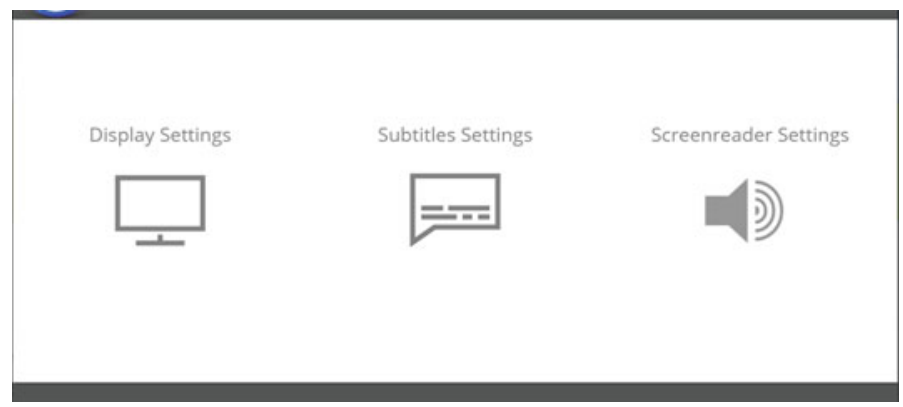

Fig. 6.4 Display functionalities

After this first attempt at generating accessible online media content, a new MOOC was designed within the European funded project ACT (Orero 2017). ACT aims at training the expert on accessibility for live cultural events: theatre productions, operas, conferences, etc. Given the fact that the MOOC trains on accessibility services for cultural contents, it had to be accessible and it was considered that a MOOC would be a good way to showcase the project.

The HBB4ALL MOOC was developed in a platform which aimed at offering accessibility services and interaction. The ACT MOOC was developed for Coursera, a standard platform which lacks most accessible functionalities, so creativity was required when dealing with services such as audio description. The solution was to apply "accessible cinema" (Romero-Fresco 2012) guidelines from the course design. For audio description this meant to include in the narrative or presentation the audio description. For example, when a teacher was introduced, the presentation included their physical appearance. When a movie was shown, the movie could not be audio described, but the approach then was to add an audio introduction (Fryer and Romero-Fresco 2014). 
ACT took care to find out user requirements from the three groups identified as "end users", ${ }^{14}$ who were:

- Managers of cultural venues;

- members of artistic teams; and

- diverse audiences including people with varying physical, linguistic, sensory, and cognitive abilities.

While in the HBB4ALL MOOC persons with disabilities (PwD) were the focus of interaction, for ACT MOOC they were only one of the three groups used to gather requirements. For this ACT MOOC there were two challenges:

- The use of Coursera as a closed and standardise platform didn't allow for any accessibility add-on services.

- PwD were no longer the target student.

Looking at the bibliography on accessibility and MOOCs to understand solutions it became clear the approach used to gather requirements. Sánchez-Gordón and Luján-Mora (2016) literature review shows that to date end user requirements are gathered following the UN International Classification of Functioning, Disability and Health WHODAS $2.0^{15}$ :

- Blindness and low vision

- Deafness and reduced hearing needs

- Speech needs

- Motor needs

- Cognitive needs

- Psychological needs

- Elderly needs

- Non-native speakers' needs

- Cross-cultural needs

- Technology needs.

Out of the ten categories only the last three are not health-related. This biased profiling approach has a direct implication in three areas:

- It displaces learning from a universal human right to an "Assisted Living" territory, where each medical condition requires a uniquely designed solution.

- Assisted living raises the issue of "reasonable accommodation" as a possibility to avoid thinking about accessibility solutions as a default usability feature.

- Defines profiling from a pathological perspective, reinforcing the bipolar inclusive/exclusive model, away from mainstreaming possibilities.

Designing the two MOOCs, and looking at ways to optimise accessibility services for PwD made us identify the basic flaw: profiling end users from a Medical Model. MOOCs are related to learning, and access to content and interaction is more related

\footnotetext{
${ }^{14}$ See http://pagines.uab.cat/act/content/io1-accessibility-profiling [retrieved 14/03/2018].

${ }^{15}$ See http://www.who.int/classifications/icf/en/ [retrieved 14/03/2018].
} 
to capabilities than to disabilities. The MOOCs we generated will not solve the functioning or health items gathered by Sánchez-Gordón and Luján-Mora (2016) since interaction is related to communication. It is for this reason that for the ACT MOOC, and the research we have currently embarked in other $\mathrm{H} 2020$ funded projects (1), we decided to challenge the medical approach to understand end user needs. The objective is to mainstream media accessibility in all human communication activities, such as learning, where media is nowadays the most popular format. In order to propose a new profiling model, a critical revision of existing models is performed in the next section.

\subsection{Background: The Most Common Models of Disability}

Disability has always been difficult to define, no matter what approach is chosen. One of the reasons may be that "disabled people belonging to the same "impairment category' as those who have visual, hearing or mobility impairments vary enormously" (Marks 1997: 85). Nevertheless, that is no excuse to not being able to identify it, since it still needs to be dealt with. To be able to stand up to scrutiny, a definition of disability should be applicable to all people, without segregation into groups such as "the visually impaired" or "the hearing impaired", and be able to describe the experience of disability across many areas of functioning (Leonardi et al. 2006). It is not a matter of benevolence, but, as we have previously stated, of Human Rights. Although disability has traditionally been closely linked to medical models, there are also other approaches that try to tear the medical tags in order to place the disabled person in context. Actually, it is a matter of fact that more recent models of disability acknowledge the central role of social factors in understanding the causes and consequences of disability, supporting a more integrative biopsychosocial model of disability (Peterson and Elliott 2007). This variety of models is what makes the definition of disability so hard to come up with; however, at the same time, this wide range of ideas evidences the effort that has been put towards attaining one goal: understanding disability from different angles to achieve full inclusion.

In this section presented some of the most traditional and used models to classify disability are going to be put forward, as well as some new approaches, so as to analyse their strong points and weaknesses, always bearing in mind that our final objective is to find an approach that allows non-medical researchers, in this case researchers who want to develop accessible learning tools for the disabled, to design research materials, such as questionnaires, which can truly be helpful to obtain the needed information that can be both useful and relevant. 


\subsubsection{The Moral Model}

Even though it may sound dated, it is worth mentioning due to it being the oldest paradigm for understanding disability in the Western World. Based on religious beliefs, it considers disability a test of faith, the notion that "God gives us only what we can bear". The Moral Model links disability with sin and shame. In this sense, as disability impairs one sense, it heightens another (Olkin 2001). Charity and condescendence are the social reply to disability, and while the concept is dated, is very much alive today. It is common to find someone speaking slowly to someone in a wheelchair or helping a blind person to cross the street. These today are considered morally good actions.

\subsubsection{The Medical Model}

The Medical Model takes the moral aspect out and substitutes it for a more patronising perspective. It is not an explicitly described model, but rather label attached to a large body of research with a focus mainly on biomedical explanations (Bøttcher and Dammeyer 2016). According to this model, disability is a pathological and permanent issue that exclusively belongs to the disabled person, and that needs to be fixed, even if it does not cause pain or illness. For example, if a signing deaf person wants to attend a university lecture but is unable to do so because there is no Sign Language interpreter, the Medical Model would suggest that this is because of the person's hearing loss problems, rather than the lack of Sign Language interpreters. Another example would be a researcher who refuses to produce a questionnaire in a larger font for a visually impaired person. By doing so, the researcher is depriving that particular informant of participating.

This kind of approach has proved to be beneficial to improve medical diagnosis and treatment and, thus, to have better results in that particular field, but it also has a series of weaknesses. Doctors are the experts, whereas patients are passive and not collaborators. The goal is to "fix" what is "wrong" with the person aiming at "normality". The problem is individual isolated from society; the fact that it creates low expectations and results in people losing independence and choice; and, finally, its lack of human touch. It can be seen that this model fails to empower people with disabilities and to make inclusion a reality. This model emphasizes the injury that leads to disability rather than the individual, and, therefore, people can be regarded as disabled only because of the characteristics of some organs, which are seen as a whole, which, in turn, causes the subject to be lost (Edler 2009). 


\subsubsection{The Social Model}

The Social Model, was developed in opposition to the medical approach, first in the United Kingdom in the 1960s and 1970s (Bøttcher and Dammeyer 2016). It was mainly developed by Michael Oliver, who "sees disability, by contrast with impairment, as something imposed on disabled people by oppressive and discriminating social and institutional structures" (Terzi 2005: 201). It believes the medical explanation is insufficient to understand the relationship between people and their environment, and that not enough importance is attached to human diversity (Edler 2009). The Social Model shifts the focus from the defective person to society . Disability now is not the physical impairment, but the failure of society to consider individual differences (Bøttcher and Dammeyer 2016). According to this model, impairments are not what makes people disabled, but the world around them. This is to say negative connotations, social barriers and lack of accessibility are the actual problem, not disability itself. Disability is an experience, not an injury (Edler 2009). Using one of the examples presented in the previous model, the problem of the deaf person being unable to attend a lecture would be the lack of Sign Language interpreters at that university, not the person's hearing impairment. Thus, accessibility is seen as a matter of civil rights, as the way to balance the treatment that society offers to its citizens. This model concludes that accessibility makes the world less disabled and leaves people just with their impairments.

Nonetheless, the popularity of the Social Model has been increasingly criticised in the past number of years, mainly for ignoring that disabilities are grounded in biological impairments, and for overlooking individual psychological perspectives of people with disabilities (Bøttcher and Dammeyer 2016). According to Shakespeare, "the simplicity which is the hallmark of the social model is also its fatal flaw" (Shakespeare 2010: 271) since it misses a disability as a core feature of many disabled people's lives and the concept of the barrier-free utopia. Terzi (2005) considers there is an aspect of over-socialization of sources and causes of disability and the model overlooks the complex dimensions of impairment.

\subsubsection{The Human Rights Model}

As previously stated, the Social Model of disability was developed as a critique to the Medical Model of disability; however, within disability studies, the Social Model of disability has been almost as condemned as the Medical Model (Degener 2016). The UN CRPD was initially drafted as a human rights convention that aimed to substitute the Medical Model of disability for the Social Model of disability. Yet, according to Degener (2016)-who in 2001 was a legal expert to the UN High Commissioner for Human Rights as co-author of the background study to the UN CRPD-the drafters went beyond the Social Model and came up with a treaty based on the Human Rights Model of disability (in fact, what these two models have in common is that both are 
built on the premise that disability is a social construct). Thus, the Human Rights Model offers an alternative to both the Social and Medical Models of disability and is a tool to implement the CRPD.

Degener (2016) suggests six propositions to explain in which ways the Human Rights Model differs from the Social and also why it goes one step further:

- The human rights model can vindicate that human rights do not require a certain health or body status, whereas the social model can merely explain that disability is a social construct.

- The human rights model encompasses both sets of human rights, civil and political as well as economic, social and cultural rights and thus not only demands antidiscrimination rights for disabled persons.

- The human rights model embraces impairment as a condition which might reduce the quality of life but which belongs to humanity and thus must be valued as part of human variation.

- The human rights model values different layers of identity and acknowledges intersectional discrimination.

- Unlike the social model, the human rights model clarifies that impairment prevention policy can be human rights sensitive.

- It is thought that the human rights model not only explains why $2 / 3$ of the world's disabled population live in developing countries, but that it also contains a roadmap for change. Degener (2016: 19).

Regarding its weaknesses, Berghs et al. (2016) underline that many analyses have identified non-enforcement as a problem, and there is evidence of a lack of defined sanctions. Moreover, people with disabilities hold the belief that the link between the CRPD and other legislative institutions is still unclear. A frequent issue linked to the implementation and enforcement of the CRPD is how to understand what 'reasonable accommodation' means. This has particular implications for research. "The way environments should be 'modified' to accommodate and ensure disabled people can exercise their rights is open to interpretation. [...] Inclusion tends to be defined in relation to access and, ignoring diversity among people with disabilities, assumes a universal research design will solve problems for all” (Berghs et al. 2016: 35).

\subsubsection{The International Classification of Functioning Model}

The International Classification of Functioning, Disability and Health (ICF) was approved by the World Health Organisation in 2001 and has been yearly revised since then, the last version being approved in 2017. Based on, theoretically, the integration between the Social and Medical Model of disability and initially drafted as the International Classification of Impairments, Disabilities, and Handicaps (ICIDH), the ICF was intended to complement its sister classification system, the International Classification of Diseases (ICD). The ICD classifies mortality and morbidity, whereas the ICF classifies functioning, disability, and health, and they are designed to be 
used together (Peterson and Elliott 2007). The ICF Model sees disability as the result of a combination of individual, institutional and societal factors that define the environment surrounding a person with an impairment (Dubois and Trani 2009). It is operationalised through the World Health Organization Disability Assessment Schedule II (WHODAS II) and it covers all types of disabilities, for various countries, languages and contexts, which makes it suitable for cross-cultural use.

The aims of the $\mathrm{ICF}^{16}$ (WHO 2001: 5) are to:

- Provide a scientific basis for understanding and studying health and health-related states, outcomes, determinants, and changes in health status and functioning;

- establish a common language for describing health and health-related states in order to improve communication between different users, such as health care workers, researchers, policy-makers and the public, including people with disabilities;

- permit comparison of data across countries, health care disciplines, services and time; and

- provide a systematic coding scheme for health information systems.

ICF's novelty is combining health functionality with contextual factors (gender, race, age, fitness, religion, lifestyle, habits, upbringing, behaviour pattern and character, etc.), which supposedly gives it a biopsychosocial and interactional approach. It is believed that all these descriptors can impact health and functioning, and users are encouraged to consider these issues qualitatively while classifying other areas of health and functioning. Great interest has been expressed by a variety of stakeholders to further develop this component of the ICF (e.g., Hurst 2003).

The ICF has gained considerable influence globally. It is used for a variety of objectives, in descriptive as well as analytical studies and for policy. Yet, its rigid classification fails to reproduce a more accurate picture of the reality.

\subsection{The Human Development Model of Disability, Health and Wellbeing (HDM)}

Amartya Sen, 1998's winner of the Nobel Prize of Economics, along with Martha Nussbaum, are responsible for developing the capability approach, which has been used as a framework to analyse different concepts in welfare economics (Mitra 2006). This has been extrapolated to many different fields of knowledge to address a wide range us issues, such as: poverty, justice and even in disability studies. Under the capability approach, Sen and Nussbaum focus on the type of life that people are able to live, i.e., on their practical opportunities, called, according to these two authors, capabilities, and on their achievements, called functionings (Mitra 2006). Sen used the example of two women starving to contrast the two terms: both women have the same functioning (not being well nourished) but very different capabilities. One

\footnotetext{
${ }^{16}$ See http://www.who.int/classifications/icf/en/ [retrieved 05/03/2018].
} 
has the capability, this is, the opportunity to be well nourished but decides to starve for her religious beliefs, and the other can't afford to buy food. This approach has also given rise to a new model of disability: The Human Development Model of Disability, which aims at providing a conceptual framework to describe and explain health conditions, impairments, disability, their causes as well as their consequences (Mitra 2018).

Disability can be understood as a deprivation in terms of capabilities or functionings that results from the interaction of an individual's (a) personal characteristics (age, impairment, etc.) and (b) available goods (assets, income) and (c) environment (social, economic, political, cultural) (Mitra 2006). Disability means lacking certain capabilities/functioning due to the interaction of the above-mentioned factors. Thus, disability depends on whether the impairment places restrictions on the individual functioning or capabilities.

It is worth to retrieve the example Mitra (2006) mentions in her article to explain how she departs from the Capabilities Approach to develop a new model of disability: a 19-year-old boy who suffers a brain injury is considered disabled if his practical opportunity to attend college is restricted (potential disability), in contrast to an individual with a similar basket of goods, in the same environment, and with similar personal characteristics except for the impairment. In case the 19-year-old cannot finally attend college, we would be facing actual disability but in case he finally goes to university, then he would not be considered disabled.

The Human Development Model uses capabilities and/or functionings as metric for wellbeing (Mitra 2018). It does not consider impairments/health conditions as individual characteristics; instead, they are themselves determined by resources, structural factors, and personal characteristics, and thus the model is informed by the socioeconomic determinants of health literature.

Mitra (2018) states that for the Human Development Model (HDM) the focus is on how health deprivations may relate to other dimensions of wellbeing. The aim of research or policy initiatives guided by this model is thus to enhance human development, this is, to expand the functionings/capabilities of individuals with health deprivations or to expand functionings/capabilities by preventing health deprivations.

Unlike the Social and Medical models, but like other interactional models such as the ICF, the human development model provides a comprehensive account of the variety of factors that might lead to deprivations. According to the HDM, and unlike the Medical Model, the impairment is not always the cause for disability and, unlike the Social Model, the environment is not always the disabling factor. Also, the ICF could benefit from becoming open-ended, with the recognition that not all dimensions of life may be specified and classified, and thus the classification does not, and cannot be expected to provide an exhaustive account of the lived experience of health deprivations.

It is with this HDM as a framework where user interaction requirements for accessing media learning environments should be based. In order to apply this new model to profile requirements. 


\subsection{Drafting User Experience Questionnaires}

Traditionally, user interaction with persons with disabilities requested for the user to tick if they were: blind or low sighted or deaf and hard of hearing. Some even went as far as asking the $\%$ of disability in their condition. While offering important information regarding their condition, other more important traits were overseen, for example, if a person is a fast reader. After many tests across Europe (Romero-Fresco 2015), it was found that reading subtitles was not related to any condition, but to reading ability, usually related to education. Consequently, we feel it is high time to take into consideration a new approach when designing the steps of a process aiming at offering any e-learning product taking user needs and requirements into account.

As we have already seen, under Sen's approach, disability can be understood as a deprivation in terms of capabilities or functionings that results from the interaction of an individual's (a) personal characteristics (age, impairment, etc.) and (b) available goods (assets, income) and (c) environment (social, economic, political, cultural) (Mitra 2006). This is to say that disability means lacking certain capabilities/functionings due to the combination of the above-mentioned factors. Consequently, when working with users to design any content, platform or technology for e-learning two issues need to be considered: (a) their capabilities and functionings (where they are and where they want to be) and (b) their personal characteristics, commodities and environment.

To design the methodology of any project aiming at producing e-learning materials for all citizens we suggest the following steps.

1. First of all gather a small group of people representing end user capabilities to collect information regarding expectations and needs. This stage is basic also to understand the validation process. The users in this first interaction can be called "super users" since, besides their condition of regular users, they also have some knowledge on the items to be tested. It would make no sense to consult users with no knowledge or experience with neither functional diversity nor technological background since at this stage what we require is not their acceptance of the final service, but system requirements.

These "super users" can be interviewed in focus groups or requested information through a questionnaire, or both, for example. Some questions that could be asked are:

- What are the key capabilities/functionings that you value when it comes to...?

- What level of achievement would be sufficient?

2. Testing e-learning technology/platform/content with users.

After developing the requested functionalities, a further interaction with superusers is needed to check if needs and expectations were met.

3. Once the integration has taken place, interaction with end users take place. To this aim two questionnaires can be drafted-one to be answered before the test and the other one just after. 
- In the first questionnaire end users map their current situation regarding the capabilities/functionings mentioned by super-users. To evaluate capabilities/functionings, question should be like: "Do you have difficulty in...?" and then offer a scale.

- After end users test the new e-learning content/platform/technology, a postquestionnaire is distributed, which has to reproduce the same questions regarding capabilities/functionings to understand their assessment. Also, a demographic section needs to be included to ask about personal characteristics, commodities and environment, which are the factors that can lead to disability.

- Capability based questionnaires will not offer quantitative profiling, as ICT does. Rather than considering students by their officially established \% of disability, their impairment will be evaluated towards a dynamic evaluation and functional profile.

\subsection{Conclusions}

The chapter has revised the legal background required to guarantee access for all to educational e-content and applications, from a Human Right perspective, securing the accessibility of media formats used for education. While the legal framework is in place, and to some extent technologies and standards are available, the main e-learning platforms are not accessible. This Accessibility decreases further when dealing with the user interaction to learning content, usually in audiovisual formats.

In this chapter the experience of designing two MOOCs to teach media accessibility are described. The first is a MOOC designed to be accessible, showcasing the many technological available options to secure access. The second MOOC uses a ready platform, Coursera, that challenged accessibility, but some solutions were found. The design of the two MOOCs shared the user centric methodology where persons with disabilities defined interaction requirements. Data from this interaction is usually gathered through questionnaires, which need to address the functionality of the interaction (impairment), rather than the user physiological condition (disability). For example, the literature showed that screen reading (subtitles) is associated to persons with hearing impairments. The chapter proposes a new approach to profiling students to design and validate e-learning platform requirements. The use of a capability approach-based model to reflect the needs of all citizens in society, following a Universal Design approach to mainstream accessibility. Adapting Sen's capability model to education and student profiling should offer an open-ended capability approach rather than a prescriptive medical taxonomy. It is expected that the proposal presented in this chapter should open the door to mainstreamed accessibility. This new impairment and capability — rather than disability — perspective has many implications for all issues related to e-learning and the future of student interaction with multimedia educational content. It is hoped this chapter raises awareness on the 
need to implement accessibility in the production phase of any learning material to secure universal access to all.

\section{References}

Berghs MJ, Atkins KM, Graham H (2016) Scoping models and theories of disability. Implications for public health research of models and theories of disabilities: a scoping study and evidence synthesis. Public Health Res 4(8):23-40

Bohnsack M, Puhl S (2014). Accessibility of MOOCs. In: Proceedings of the 14th international conference of computers helping people with special needs (ICCHP 2014), pp 141-144. https:// doi.org/10.1007/978-3-319-08596-8_21

Bøttcher L, Dammeyer J (2016) Beyond a biomedical and social model of disability: a culturalhistorical approach. In: Development and learning of young children with disabilities. International Perspectives on Early Childhood Education and Development, vol 13. Springer, Cham, $3-23$

Degener T (2016) Disability in a human rights context. Laws 5(3):35

Dubois J, Trani J (2009) Extending the capability paradigm to address the complexity of disability. ALTER, Eur J Disabil Res 3:192-218

Edler R (2009) La clasificación de la funcionalidad y su influencia en el imaginario social sobre las discapacidades. In: Brogna P (ed) Visiones y revisiones de la discapacidad. Fondo de Cultura Económica, México D.F., pp 137-157

Fryer L, Romero-Fresco P (2014) Audio introduction. In: Maszerowska A, Matamala A, Orero P (eds) Audio description: new perspectives illustrated. John Benjamins, Amsterdam, pp 11-28

Greco GM (2016) On accessibility as a human right, with an application to media accessibility. In: Matamala A, Orero P (eds) Researching audio description: new approaches. Palgrave, London, pp 11-33

Hurst R (2003) The international disability rights movement and the ICF. Disabil Rehabil 25:572-576

Iniesto F, Rodrigo C, Teixeira AM. (2014). Accessibility analysis in MOOC platforms. A case study: UNED COMA and UAB iMOOC. In: International conference on quality and accessibility of virtual learning (CAFVIR 2014), pp 545-550

Iniesto F, Rodrigo C (2016) Strategies for improving the level of accessibility in the design of MOOC-based learning services. In: IEEE international symposium on computers in education (SIIE 2016), pp 1-6. https://doi.org/10.1109/siie.2016.7751841

Leonardi M, Bickenbach J, Ustun TB, Kostanjsek N, Chatterji S, MHADIE Consortium (2006) The definition of disability: what is in a name? Lancet 368(9543):1219-1221

Marks D (1997) Models of disability. Disabil Rehabil 19(3):85-91

Mitra S (2006) The capability approach and disability. J Disabil Policy Stud 16(4):236-247

Mitra S (2018) The human development model of disability, health and wellbeing. In: Disability, health and human development. Palgrave Studies in Disability and International Development. Palgrave Pivot, New York

Ngubane-Mokiwa SA (2016) Accessibility strategies for making MOOCs for people with visual impairments: a universal design for learning (UDL) perspective. In: 8th pan-commonwealth forum on open learning (PCF8)

Olkin R (2001) What psychotherapists should know about disability. The Guilford Press, London, New York

Orero P (2017) The professional profile of the expert in media accessibility for the scenic arts. Rivista internazionale di tecnica della traduzione 19:143-161 
Pascual J, Castillo C, García-Díaz V, González R (2014) Method for analysing the user experience in MOOC platforms. In Proceeding of IEEE international symposium on computers in education (SIIE 2014), pp 157-162. https://doi.org/10.1109/siie.2014.7017722

Peterson D, Elliott T (2007) Advances in conceptualizing and studying disability. In: Brown S, Lent R (eds) Hand book of counseling psychology. John Wiley, Hoboken, NJ, pp 212-230

Romero-Fresco P (2012) Accessible filmmaking: joining the dots between audiovisual translation, accessibility and film making. JosTrans 20:201-223

Romero-Fresco P (2015) The reception of subtitles for the deaf and hard of hearing in Europe. Peter Lang, Bern

Seale JK (2014) E-learning and disability in higher education: accessibility research and practice. Routledge, London

Sanchez-Gordon S, Luján-Mora S (2014) Web accessibility requirements for massive open online courses. can MOOCs be really universal and open to anyone? In: Conference on quality and accessibility of virtual learning (CAFVIR 2014), pp 530-535

Sanchez-Gordon S, Luján-Mora S (2015) Accessible blended learning for non-native speakers using MOOCs. In: Proceedings of IEEE international conference on interactive collaborative and blended learning (ICBL), pp 19-24. https://doi.org/10.1109/icbl.2015.7387645

Sánchez-Gordón S, Luján-Mora S (2016) Research gaps in ccessibility and MOOCs: a systematic literature review 2008-2016. http://hdl.handle.net/10045/61628

Shakespeare T (2010) The social model of disability. In: Lennar J (ed) The disability studies reader. Routledge, New York, pp 266-273

Szarkowska A, Krejtz I, Krejtz K, Duchowski A (2013) Harnessing the potential of eye-tracking for media accessibility. In: Grucza S, Płużyczka M, Zając J (eds) Translation studies and eye-tracking analysis. Peter Lang, Frankfurt am Main, pp 153-183

Terzi L (2005) A capability perspective on impairment, disability and special needs: towards social justice in education. Theory Res Edu 3(2):197-223

Open Access This chapter is licensed under the terms of the Creative Commons Attribution 4.0 International License (http://creativecommons.org/licenses/by/4.0/), which permits use, sharing, adaptation, distribution and reproduction in any medium or format, as long as you give appropriate credit to the original author(s) and the source, provide a link to the Creative Commons license and indicate if changes were made.

The images or other third party material in this chapter are included in the chapter's Creative Commons license, unless indicated otherwise in a credit line to the material. If material is not included in the chapter's Creative Commons license and your intended use is not permitted by statutory regulation or exceeds the permitted use, you will need to obtain permission directly from the copyright holder.

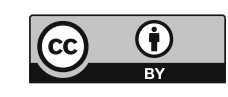

